Tropical Journal of Pharmaceutical Research January 2016; 15 (1): 115-119

ISSN: $1596-5996$ (print); 1596-9827 (electronic)

(C) Pharmacotherapy Group, Faculty of Pharmacy, University of Benin, Benin City, 300001 Nigeria.

All rights reserved.

Available online at http://www.tjpr.org

Original Research Article

http://dx.doi.org/10.4314/tjpr.v15i1.16

\title{
Effect of Low Level Cadmium Exposure on Superoxide Dismutase Activity in Rat
}

\author{
Olabisi O Ogunrinola*, Dorcas A Wusu, Olusegun O Fajana, Samuel N Olaitan, \\ Zainab O Smith and Abdul-Rahman I Bolaji \\ Cell and Tissue Culture Research Laboratory (Drug Discovery Unit), Department of Biochemistry, Lagos State University, Ojo, \\ PMB 0001, LASU Post Office, Lagos - Badagry Expressway, Lagos, Nigeria
}

*For correspondence: Email: olabisi.ogunrinola@lasu.edu.ng, ooogunrinola@yahoo.com; Tel: +234(0)803324476

\begin{abstract}
Purpose: To investigate the effect of low level cadmium (Cd) exposure on the activity of superoxide dismutase $(S O D)$ in rat.

Methods: Thirty-two male albino rats were divided into four groups of eight animals each. Group one received distilled water and served as control. The other three groups were exposed to 100, 200 and 300 ppm cadmium doses, respectively, in their drinking water for 6 weeks. At the end of 6 weeks, blood, brain and liver were removed from the animals and SOD activities were investigated spectrophotometrically at $480 \mathrm{~nm}$.

Results: The data revealed a significant $(p<0.05)$ decrease in organ weight of the exposed rats, and with the highest cadmium accumulation in liver ranging from $2.99 \pm 0.20 \mu \mathrm{g} C / \mathrm{g}$ tissue in control to $34.57 \pm 2.06 \mu \mathrm{g} \mathrm{Cd} / \mathrm{g}$ tissue for the $300 \mathrm{ppm}$ dose group. Exposure to cadmium resulted in significant ( $p$ $<0.05)$ decrease in SOD activity in plasma, erythrocytes, brain and liver in a dose-dependent manner compared to control. The data showed a negative correlation between tissue cadmium and SOD in plasma, erythrocyte and brain. While positive associations were observed between blood and tissue (brain and liver) cadmium and SOD, a significant $(p<0.01)$, negative correlation was found between tissue cadmium and SOD.

Conclusion: As Cd dose increase, plasma, erythrocyte, brain and liver SOD activities decrease. This might affect the maintenance of the normal body physiological conditions.
\end{abstract}

Keywords: Cadmium, Superoxide dismutase, Liver, Brain, Toxicity, Environmental contaminant

Tropical Journal of Pharmaceutical Research is indexed by Science Citation Index (SciSearch), Scopus, International Pharmaceutical Abstract, Chemical Abstracts, Embase, Index Copernicus, EBSCO, African Index Medicus, JournalSeek, Journal Citation Reports/Science Edition, Directory of Open Access Journals (DOAJ), African Journal Online, Bioline International, Open-J-Gate and Pharmacy Abstracts

\section{INTRODUCTION}

Cadmium $(\mathrm{Cd})$ is a serious environmental and occupational contaminant that may represent a serious health hazard to humans and other animals. The increased discharge of cadmium from industrial process, waste disposal and cigarette smoke in the environment leads to a general fear for the potential toxic effects of cadmium. Since cadmium cannot be degraded, the risk of environmental exposure is constantly increasing because of accumulation via the food chain [1]. Exposure to this toxic metal at the cellular level can produce both acute and chronic tissue injury and can damage various organs including lung, liver, kidney, bone, testis and placentas depending on the dosage, route and duration of exposure causing several damages $[2,3]$. The generation of reactive oxygen species (ROS) followed by development of oxidative stress in the target organs is one of the several mechanisms through which cadmium exerts its 
toxicity [4]. Vulnerability to stress alters the normal body homeostasis and leads to the development of various pathologies, which may involve alterations in the antioxidant defense system such as superoxide dismutase. Antioxidants may be enzymatic or non-enzymatic and are intimately involved in the prevention of cellular damage - the common pathway for cancer, aging and a diversity of diseases [5].

Superoxide dismutase is an important enzyme family in living cells for maintaining normal physiological conditions and for coping with stress. The role of superoxide dismutase, therefore, is to protect the biological integrity of the cells and tissues against harmful effects of superoxide free radical [6]. Since the implication of cadmium toxicity on disruption of the oxidative antioxidant defense system depends on route of administration, dose and duration of exposure, we propose to investigate the effect of low level of cadmium exposure through drinking water for six weeks on superoxide dismutase activity in adult male rat.

\section{EXPERIMENTAL}

\section{Animals and experimental design}

Thirty-two adult male albino rats (Wistar strain) weighing between 180 to $200 \mathrm{~g}$ were purchased from Nigerian Institute of Medical Research, Yaba, Lagos, Nigeria. They were housed in animal stainless steel cages with a $12 \mathrm{~h}$ light/dark cycle and free access to food and water for 14 days prior to the experiment.

The animals were randomly and equally distributed into four groups with eight rats in each group. Animals in group one were given distilled water and served as controls while rats in three other groups were given 100, 200 and 300 ppm cadmium in drinking water, respectively. All groups were fed ad libitum with growers mash (product of Animal Care, Lagos, Nigeria). They were all exposed to this treatment for six weeks. At the end of the treatment period, the rats were weighed and sacrificed under light ether inhalation anesthesia. The blood was collected, centrifuge into plasma and erythrocyte while the brain and liver were quickly excised, weighed and placed on ice until required for biochemical analysis. All the animal protocols conformed to the guiding principles of laboratory animal care (NIH Publication No. 85-93, revised 1985) [7] and were approved by the adhoc animal ethical committee (ref no. $\mathrm{BCH}-05 / 2007$ ) of the Department of Biochemistry, Lagos State University, Ojo, Lagos, Nigeria.

\section{Superoxide dismutase assay}

An indirect method of inhibiting auto- oxidation of epinephrine to its adrenochrome was used to assay superoxide dismutase (SOD) activity [8]. The $10 \%$ homogenate, each of brain and liver, respectively, was prepared with chilled $0.9 \%$ $\mathrm{NaCl}$ solution and centrifuged at $3,000 \mathrm{~g}$ for 10 min. The plasma, erythrocyte, homogenates of the brain and liver SOD was determined spectrophotometrically at $480 \mathrm{~nm}$ (model SM 755s, Surgienfield Instrument, Zhejiang, China. SOD activity was expressed in unit/ml for plasma and erythrocyte while that of the brain and liver homogenates were expressed in unit/g tissue. Erythrocyte SOD activity was assayed on the basis of the inhibition of adrenaline autoxidation. Briefly, to erythrocyte hemolysate, $333 \mu \mathrm{M}$ solution of adrenalin in $50 \mathrm{mM}$ carbonate, $\mathrm{pH}$ 10.2, containing $100 \mu \mathrm{M}$ EDTA was added. The absorbance of the solution was monitored spectrophotometrically at $480 \mathrm{~nm}$ as a function of time at $37^{\circ} \mathrm{C}$. The degree of inhibition of the maximal rate of absorbance increase was taken as a measure of SOD activity. One unit of SOD is the amount of the enzyme required for $50 \%$ inhibition of the auto-oxidation of epinephrine to adenochrome per minute. The blood and organ cadmium concentrations were determined by atomic absorption spectrophotometry (Model NC 942340030042, product of Thermo Fisher Scientific Company, USA) after digestion with concentrated trioxonitrate (V) acid.

\section{Statistical analysis}

The assay was performed in triplicate and results were expressed as mean \pm SEM. Statistical differences in the means were determined using one-way analysis of variance (ANOVA) followed by Turkey's test (Turkey honest significant difference (THSD)) with $p<0.05$ considered significant. The associations among the parameters and their magnitudes were tested for using multiple linear regression analysis.

\section{RESULTS}

A gradual decrease was observed in the relative weights of the organs, although this was not dose dependent. At the highest dose of cadmium, relative weights of the organs decreased as follows: brain $15 \%$ and liver $24 \%$, respectively. The result shows that cadmium uptake is high in blood, brain and liver of the animals, but the highest concentration was observed in the liver, whereas brain accumulated the least (Table I). 
Table 1: Relative organ weights ( $\mathrm{g} / 100 \mathrm{~g}$ body weight) and $\mathrm{Cd}$ concentrations in blood, brain and liver of the animals

\begin{tabular}{|c|c|c|c|c|}
\hline \multirow{2}{*}{ Organ/Blood } & \multicolumn{4}{|c|}{ Cadmium doses } \\
\hline & Control & 100 ppm & 200 ppm & 300 ppm \\
\hline \multicolumn{5}{|c|}{ Relative organ weights } \\
\hline Brain (g/100g body weight) & $1.16 \pm 0.13^{\mathrm{a}}$ & $1.09 \pm 0.13^{0}$ & $1.06 \pm 0.14^{\circ}$ & $0.99 \pm 0.10^{c}$ \\
\hline Liver (g/100g body weight) & $3.42 \pm 0.38^{\mathrm{a}}$ & $2.94 \pm 0.33^{b}$ & $2.90 \pm 0.32^{b}$ & $2.59 \pm 0.28^{c}$ \\
\hline \multicolumn{5}{|c|}{ Cd concentrations } \\
\hline Blood Cd $(\mu \mathrm{g} / \mathrm{dl})$ & $0.10 \pm 0.01^{a}$ & $0.15 \pm 0.02^{a}$ & $0.22 \pm 0.02^{0}$ & $0.25 \pm 0.02^{0}$ \\
\hline Brain Cd ( $\mu \mathrm{g} / \mathrm{g}$ wet weight) & $0.18 \pm 0.01^{\mathrm{a}}$ & $0.21 \pm 0.01^{\mathrm{D}}$ & $0.25 \pm 0.02^{\mathrm{b}}$ & $0.28 \pm 0.03^{\mathrm{b}}$ \\
\hline Liver Cd ( $\mu \mathrm{g} / \mathrm{g}$ wet weight) & $2.99 \pm 0.20^{a}$ & $15.12 \pm 0.65^{\mathrm{b}}$ & $21.00 \pm 4.14^{\mathrm{C}}$ & $34.57 \pm 2.06^{\mathrm{a}}$ \\
\hline
\end{tabular}

Values are mean \pm SEM for 8 rats in each group; values having different superscripts within a row differ significantly from each other $(p<0.05)$

There was a dose-dependent reduction in plasma superoxide dismutase activity. At the highest dose of cadmium, plasma superoxide dismutase activity decreased by $41 \%$, while, erythrocyte superoxide dismutase activity dose dependently decreased $59 \%$ of control (Fig. 1).
Cadmium exposure leads to a decrease of brain superoxide dismutase activity by $90 \%$ and a dose dependent of the $20 \%$ decrease of liver superoxide dismutase activity was observed in Fig 2.
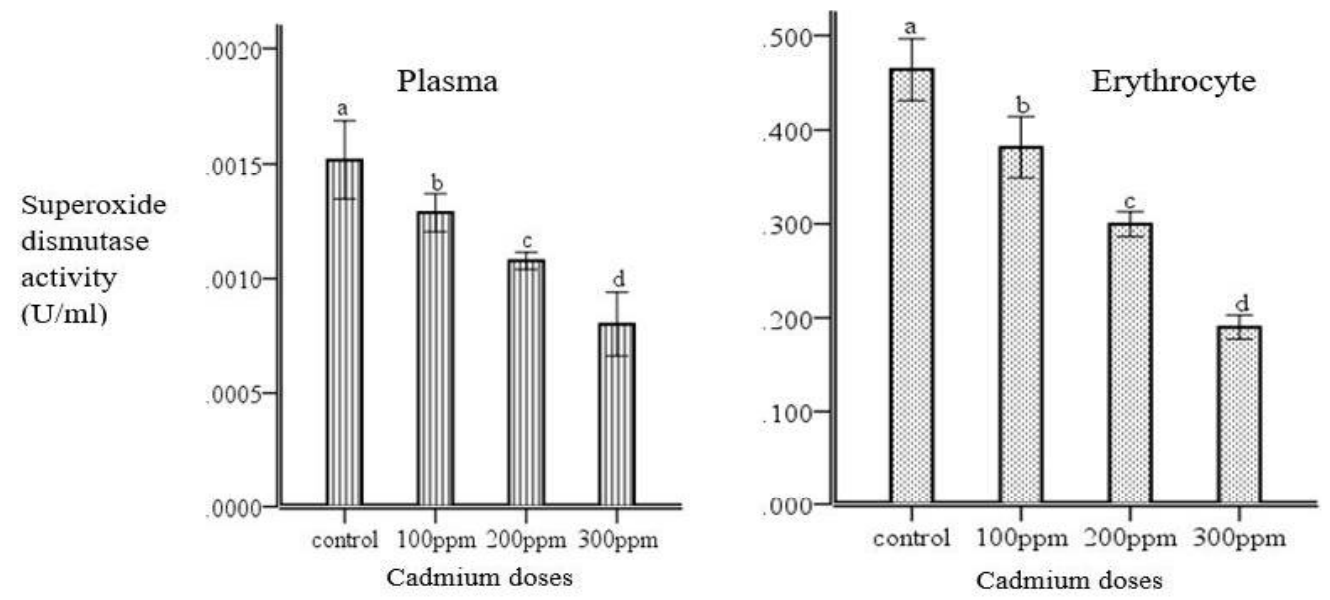

Figure 1: Effects of cadmium on plasma and erythrocyte superoxide dismutase activity. Each bar represents the mean \pm SEM $(n=8)$; bars with different alphabets are significantly different at $p<0.05$
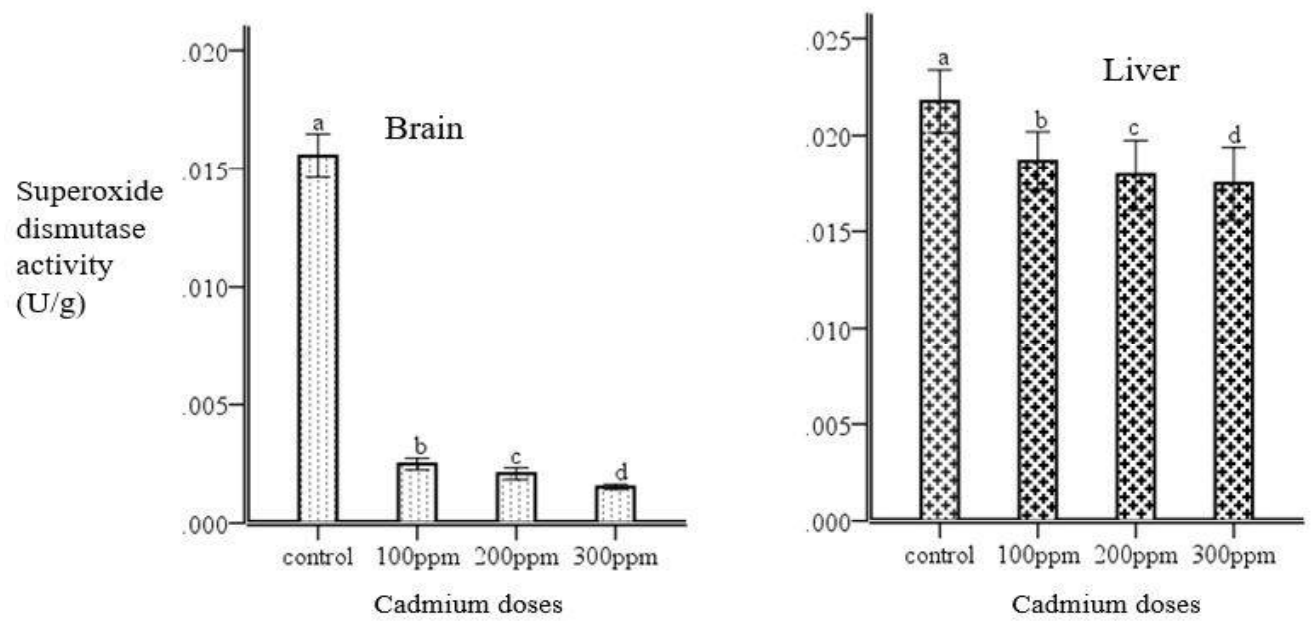

Figure 2: Effects of cadmium on brain and liver superoxide dismutase (SOD) activity. Each bar represents the mean \pm SEM $(\mathrm{n}=8)$; bars with different alphabets are significantly different at $p<0.05$ 
Table 2: Intensity of association among blood, tissue, and superoxide dismutase activity in the cadmium exposed animals

\begin{tabular}{lll}
\hline Parameter & Correlation Coefficient $(r)$ & p-Value \\
\hline Blood cadmium vs Brain Cadmium & 0.110 & 0.055 \\
Blood Camium vs Liver Cadmium & 0.122 & 0.504 \\
Blood cadmium vs plasma SOD & -0.040 & 0.829 \\
Blood cadmium vs. erythrocyte SOD & -0.305 & 0.089 \\
Blood cadmium vs brain SOD & 0.100 & 0.587 \\
Blood cadmium vs liver SOD & -0.012 & 0.947 \\
Brain cadmium vs plasma SOD & $-0.648^{\star *}$ & 0.000 \\
Brain cadmium vs erythrocyte SOD & $-0.840^{\star *}$ & 0.000 \\
Brain cadmium vs brain SOD & $-0.794^{\star *}$ & 0.000 \\
Brain cadmium vs liver SOD & -0.334 & 0.062 \\
Liver cadmium vs plasma SOD & $-0.639^{\star *}$ & 0.000 \\
Liver cadmium vs erythrocyte SOD & $-0.834^{\star *}$ & 0.000 \\
Liver cadmium vs brain SOD & $-0.798^{* *}$ & 0.000 \\
Liver cadmium vs liver SOD & -0.312 & 0.082 \\
\hline${ }_{* \star}^{* *}$ Correlation is significant at the 0.01 level
\end{tabular}

The intensities of association among the plasma, erythrocyte, brain, liver superoxide dismutase activity and blood cadmium are depicted in Table 2. Correlation, as calculated by the Pearson's method, revealed negative and positive associations among the parameters. While nonsignificant positive associations was observed between the brain, liver and brain cadmium, a significant negative association was observed between brain cadmium and the plasma SOD $(r$ $=-0.648 ; p<=0.05)$, erythrocyte SOD $(r=-$ $0.840 ; p<0.05)$ and brain SOD $(r=-0.794 ; p<$ $0.05)$; liver cadmium and the plasma SOD $(r=-$ $0.639 ; p<=0.05)$, erythrocyte SOD $(r=-0.834$; $p<0.05)$ and brain SOD $(r=-0.798 ; p<0.05)$ respectively. It was observed that non-significant correlation existed between liver SOD, blood, brain and liver cadmium.

\section{DISCUSSION}

In toxicological studies organ weight is an important parameter for evaluation of toxicity. The exposure to low level of cadmium $(\mathrm{Cd})$ in this study revealed a gradual decrease in the organ weights of the rats compared to that of the control group. This may be attributed to decreased food intake (anorexia or food avoidance) since weight gain by the organs depends on the availability of nutrients, and/or oxidative stress caused by Cd exposure. Several researchers reported a similar decrease in organ weight $[9,10]$.

The distribution of cadmium to tissues is dependent on the dose of cadmium administered. In this study, at low doses, the highest concentration of cadmium is found in the brain. However, at high doses, a greater percentage of cadmium is distributed to the liver.
Ingestion of cadmium is known to induce metallothionein (MT), a protein that is involved in detoxification of heavy metals [11]. Thus, it has been proposed that MT plays an important role in the accumulation of cadmium in the body and is responsible for the long biological half-life of cadmium [12]. Our data are in consonance with those obtained by Weigel et al [13] that liver accumulates substantial amounts of administered cadmium.

The brain is an important part of the biological system whose function helps to regulate other parts of the body. However, any damage or form of stress experienced in this part of the body may have serious impact on the entire organism. Many studies have shown that the mechanism of metal action in animals is associated with the production of reactive oxygen species and that several interpretations should be considered [14]. Firstly, cadmium causes an adverse effect on cellular defense systems and thiol status. Since metallothionein (MT) is comparatively cysteinerich and metals such as $\mathrm{Cd}$, have a high affinity for thiols, MTs are known to sequester metals. Therefore, cadmium is stored as a Cd-Mt complex in the liver. Cd-MT is metabolized in lysosomes to liberate cadmium ions. These liberated cadmium ions again bind to preexisting or newly made MT, if MT synthesis cannot keep up with the demand and the non-MT bound $\mathrm{Cd}$ overwhelms SOD defense systems, cadmium toxicity ensues [15]. The observed decrease SOD level in the liver indicates that cadmium toxicity causes oxidative stress by challenging the thiol status of cells.

Secondly cadmium has a deleterious effect on cellular enzymes. Cadmium-induces reactive oxygen species which could interact with the cellular defense via the activation of mitogen, 
activated protein kinase; c-Jun $\mathrm{N}$-terminal kinase and other signalling pathways. As a consequence, genes coding for molecules involved in the biological defense and cellular repair, including antioxidants-SOD are markedly down-regulated [16]. It has been reported that administration of cadmium, both in vivo and in vitro inhibit SOD activity [17], this is in accordance with the result of this study where administration of cadmium inhibited the activity of SOD in the tissue dose dependently.

Irrespective of the mechanism, our results suggest that plasma SOD may serve as an indicator of the balance between the damaging effects and the bio-scavenging capability of superoxide. This study showed that SOD activity decreased significantly in the brain homogenate of the rats in a dose dependent manner compared to control and may be as a result of imbalance between oxidants and antioxidants level leading to oxidative stress in the brain cell [18].

\section{CONCLUSION}

The results of the present study provide evidence that exposure to low level $\mathrm{Cd}$ has toxic effect on erythrocyte, brain and liver SOD activities.

\section{ACKNOWLEDGEMENT}

The authors greatly appreciate the judicious guidance and constructive encouragement of Professor BO Elemo, Biochemistry Department, Lagos State University, Ojo, Lagos-Nigeria and Prof. A. Ademuyiwa, Biochemistry Department, Federal University of Agriculture, Abeokuta, Ogun-Nigeria, for the successful completion of this project. We also acknowledged the assistance of the technical staff of Cell and Tissue Culture/Drug Discovery Lab, Department of Biochemistry, Faculty of Science, Lagos State University, Ojo Lagos, Nigeria during the course of this study.

\section{REFERENCES}

1. Nriagu J. A silent killer of environmental metal poisoning. Environ Pollut 1988; 50: 139-161.

2. Jarup L, Akesson A. Current status of cadmium as an environmental health problem. Toxicol Appl Pharmacol 2009; 238: 201-208.

3. Jarup $M$, Berglund $M$, Elinder $C-G$, Nordberg $G$, Vahter $M$. Health effects of cadmium exposure. A review of the literature and a risk estimated. Scand J Work Environ Health 1998; 24: 1-51.
4. Casalino E, Calzaretti G, Sblano C, Landriscina C. Molecular inhibitory mechanisms of antioxidant enzymes in rat liver and kidney by cadmium. Toxicol, 2002; 30: 37-50.

5. Pejic S, Stojiljkovic V, Todorovic A, Pajovic S. CuZnSuperoxide dismutase in brain of rats exposed to acute, chronic or combined stress. Biotechnol Biotechnol Eq 2006; 20(1): 166-122.

6. Babu KR, Rajmohan HR, Rajan BK, Kumar KM. Plasma lipid peroxidation and erythrocyte antioxidant enzymes status in workers exposed to cadmium. Toxicol Ind Health 2006; 22: 329-335.

7. Guide for the Care and Use of Laboratory Animals. NIH Publication No. 85-23. Revised 1985.

8. Misra HP, Fridovich I. The role of superoxide ion in the auto-oxidation of epinephrine and a simple assay for superoxide dismutase. J Biol Chem 1972; 247: 31703175.

9. Asagba SO, Eriyamuremu GE. Oral cadmium exposure and levels of superoxide dismutase, catalase, lipid peroxidation and ATPases in the eye. Res $J$ Environ Toxicol 2007; 1(4): 204-209.

10. Asagba SO, Eriyamuremu GE. Oral cadmium exposure alters hematological and liver function parameters of rats fed a Nigerian like diet. J Nutr Environ Med 2007; 16: $267-274$

11. Kotsonis FN, Klaassen $C D$. The relationship of metallothionein to the toxicity of cadmium after prolonged administration to rats. Toxicol Appl Pharmacol 1978; 46: 39-54. 12. Shaikh ZA, Jordan SA, Tewan PC. Cadmium disposition and metallothionein induction in mice: Strain-, sex-, age- and dosedependent differences. Toxicology 1993; 80: 51-70.

12. Weigel HJ, Jager HJ, Elmadfa I. Cadmium accumulation in rat organs after extended oral administration with low concentrations of cadmium oxide. Arch. Environ. Contam Toxicol 1984; 13: 279-287.

13. Ercal N, Gurer-Ohan H, Aykins-Burns N. Toxic metals and oxidative stress Part I: Mechanism involved in metal induced oxidative damage. Curr Topics iMed Chem 2001; 1: 529-539.

14. Gong $Q$, Hart BA. Effect of thiols on cadmium-induced expression of metalothionein and other oxidant stress genes in rat lung epithelial cells. Toxicology 1997; 119: 179-191.

15. Nishitai G, Matsuoka M. Differential regulation of HSP70 expression by the JNK kinases SEK1 and MKK7 in mouse embryonic stem cells treated with cadmium. J Cell Biochem 2008; 104: 1771-1780.

16. Hussain T, Shukla GS, Chandra SF. Effects of cadmium on superoxide dismutase and lipid peroxidation in liver and kidney of growing rats. In vivo and in vitro studies. Pharmacol Toxicol 1987; 60: 355-358.

17. Tobwala S, Hsiu-Jen W, Carey JW, Banks WA, Ercal N. Effects of Lead and Cadmium on Brain Endothelial Cell Survival, Monolayer Permeability, and Crucial Oxidative Stress Markers in an in Vitro Model of the Blood-Brain Barrier. Toxics 2014; 2: 258-275.

Trop J Pharm Res, January 2016; 15(1): 119 